\title{
Transcranial Doppler Sonography in Studies of Mental Effort
}

\author{
David A. Washburn, Natasha B. Schultz and Holly A. Phillips \\ Georgia State University \\ USA
}

\section{Introduction}

The history of experimental psychology - likely the history of every branch of science - is intimately and symbiotically connected with innovations in technologies and techniques for measurement. Although psychology's birth as a discipline was more about an idea (namely that mind and behavior can be studied objectively and empirically, for instance by observing how physical changes correspond to changes in experience and behavior) than about an apparatus, early advances in psychology as a science were facilitated, and in many cases catalyzed, by clever instrumentation. Often these innovations were simply novel applicants of existing technology to new scientific problems. For example, Wundt studied differences in reaction time to visual versus auditory information using a "pendulum apparatus for 'Complication' studies" (pictured in the online Museum of the History of Psychological Instrumentation at Monclair State University; http://chss.montclair.edu/ psychology/museum $\left./ x_{-} 073 . h t m\right)$. This important apparatus was basically a modified metronome. The first tachistoscope for brief presentations of visual stimuli was an apparatus that resembled a guillotine (Turtle, 1997). Mueller's memory drum, which served for decades as the standard apparatus for studying memory for lists of items, was developed from a Ludwig-Baltzar kymograph, originally designed for the recording of blood pressure (Haupt, 2001). These and thousands of other devices found new useful life as research instruments in the study of behavior, and the scientific literature grew rapidly with findings reflecting each apparatus innovation.

The intersection of experimental psychology and biology, whether the offspring of that union is the field of physiological psychology or of cognitive neuroscience, illustrates this symbiotic relationship between science and technology. For example, cognitive neuroscience was established on the insights provided through the study of animal models and clinical populations, including individuals with brain damage that occurred as a result of injury, stroke, surgery, and so forth; however, the greatest gains (at least by quantitative measures, if not also by qualitative standards) in knowledge about brain-behavior relations have come in the years since the development of techniques for single-cell recording and neuroimaging of activity, structure and function. Electroencephalograhy (EEG), the event-related potential (ERP) paradigm, single-photon emission computed tomography (SPECT), magnetic resonance imaging (MRI), diffusion tensor imaging (DTI), transcranial magnetic stimulation (TMS), and transcranial Doppler (TCD) sonography are just a few of the technology-based 
neuroimaging techniques that are revolutionizing understanding of the physiological bases of psychological processes and their disorders.

Of course, instrumentation innovations do more than just opening doors for new questions to be investigated. They also constrain in some ways the answers that are obtained for those questions. Each new type of yardstick may provide an exciting novel method for measuring, but it also specifies the units of measurement, the types of things that can readily be measured, and the kinds of things that cannot. This is equally true of more sophisticated apparatus, including those used in neuroimaging. Each technique and tool provides some distinct advantages over alternate methods, but also carries specific limitations or disadvantages.

For example, the preeminent tool for contemporary neuroimaging, MRI, provides noninvasive high-resolution structural images of the brain or other organs. Carefully combined with behavioral testing to produce the functional MRI (fMRI) paradigm, this technology yields brain activity patterns that can be registered to the structural images, and compared against baseline activity patterns to provide insights into the functions associated with brain regions or networks.

But there are limitations to the fMRI procedure, including of course that it does not really provide information about the functional and causal information about the brain regions that are relatively active during particular cognitive operations. The data provided by fMRI can be highly informative, but they are correlational in nature. Only in concert with other types of data (e.g., clinical observations of patients with brain damage, experimental work with animal models) can we infer whether these correlations reveal brain networks that are necessary and sufficient for particular cognitive competencies. Another limitation of the fMRI paradigm is a sequela of the massive amount of data that are produced in a wholebrain scan: Sophisticated techniques are required to process the data such that they support valid inferences rather than statistical artifacts that suggest localizations from spurious, correlations, including those that Vul and collaborators called "voodoo correlations" (2009). Another limitation is cost. Although the hardware, software, and procedures for doing fMRI have improved in recent years, this neuroimaging strategy is still relatively expensive. It also remains difficult to conduct fMRI research with certain populations, as the procedure requires participants to remain motionless and to tolerate the ambient noises and enclosed spaces of the magnetic chamber. Many conditions, from metal implants to certain psychological disorders, are counterindicators of fMRI, disqualifying individuals from participation for research purposes. Thus, fMRI is a powerful neuroimaging tool that has a specific utility and value, but that also has specific limitations. This of course is true of every tool. That's why a plumber or carpenter needs a box of tools, rather than one generalpurpose fix-all gadget.

In recent years, sonography has provided another instrument for the cognitive scientists' toolbox. Transcranial Doppler (TCD) sonography provides relatively inexpensive, noninvasive and painless, continuous measures of bloodflow velocity, as a proxy for neural activity, which serves as a measure of cognitive processing. TCD offers high temporal resolution-much higher, for example, than fMRI-but low spatial resolution. It is a wearable technology, and thus does not require participants to remain motionless during the test. Conditions like pacemaker implants, ferrous metal dental-work, tattoos, piercings, 
and claustrophobia that can disqualify a person from participating in an fMRI study do not affect the individual's suitability for TCD. On the other hand, it is difficult or impossible to obtain stable TCD signals from some participants, often for unknown reasons, and in every case for reasons that are not as obvious as tattoos or piercings or metallic implants. Thus, TCD studies and fMRI studies both have participant-inclusion issues, but one usually cannot predict in advance which participants will fail to produce stable TCD data. Also like fMRI, TCD produces correlational data (i.e., changes in cerebral blood flow velocity, CBFv, relative to baseline, that correspond to mental or behavioral activity).

Procedural details for TCD have been described elsewhere (e.g., Aaslid, 1987; McCartney, Thomas-Lukes, \& Gomez, 1997; Ringelstein et al., 1990; Stroobant \& Vingerhoets, 2000; Tripp \& Warm, 2007). Generally, TCD requires the use one or more (typically two, for simultaneous bilateral recordings) 2-MHz ultrasound transducers to generate and receive sonic signals. The transducers are positioned against the head at the cranial windows, or locations where the bone in the skull is thin enough (or absent altogether in the case of foramina) to permit the ultrasonic signal to pass and to be focused on one of the three major cranial arteries. TCD can be used to measure CBFv through the anterior cerebral artery, the middle cerebral artery, or the posterior cerebral artery. For most studies, the middle cerebral artery is targeted with TCD, because of the large areas that are perfused by this artery within each hemisphere; thus, the transducers are typically positioned at the transtemporal windows, at the temples on either side of the forehead, lateral to each of the eyes. By adjusting the angle at which the transducer is aimed and the depth of the sonated signal, and by examining the direction in which blood is flowing, one can identify whether the ultrasonic signal is bouncing off blood cells in the medial cerebral artery or one of the other arteries. Once the desired artery is located and a strong and stable signal is obtained, the transducers are locked in place on a headband. Subsequently, the signal provides continuous measures of $\mathrm{CBFv}$ through each transducer, even with head and body movements.

Because the speed with which blood cells move through the arteries varies across the heartbeat, the signal recorded through the TCD transducer/receivers are typically averaged across the heartbeat to produce a mean CBFv value (Saver \& Feldmann, 1993). Commercial TCD systems (such as the Nicolet Vascular/Viasys Healthcare Companion-III unit in our laboratory) compute these averages automatically, and also transform the Doppler sonography readings for visual display and digital storage. Task-related changes in mean $\mathrm{CBFv}$ values are compared to resting baseline measures. For example, one might record baseline values when participants are simply relaxing and staring at a blank wall.

Since Asslid and colleagues (1982) documented the use of TCD for recording cerebral bloodflow velocity (CBFv), the tool has been explored and tested in a wide range of studies. Clinically, the instrument is used as a diagnostic tool for examining the rate of blood flow through cerebral or other arteries, in connection with the study of stroke, coronary artery disease, and similar conditions. For the present review, we are primarily concerned with the use of TCD to measure changes in CBFv that correspond to mental activities. Increase in mental activity, as when a participant performs a cognitive operation or exerts mental effort, is associated with localized increases in neural firing. This neural activity demands additional blood flow to supply oxygen and to remove metabolic waste materials. Thus, changes in CBFv provide an index of the increase in cognition-related neural activity (e.g., 
Aaslid, 1987; Droste et al., 1989; Stroobant \& Vingerhoets, 2000) in much the same way that bioelectrical activity registered by electroencephalography electrodes and radioisotope traces used in single-photon emission computed tomography (SPECT) indicate active brain regions associated with mental functions.

\section{TCD for cognitive neuroscience}

What value is there in TCD as an indirect measure of mental activity? That is, TCD does not directly measure cognitive activity. Even if cognitive psychology could provide a behavioral task that was a pure manipulation of a single cognitive process (which is impossible, as even the simplest tasks allow that multiple cognitive operations - perception, attention, memory, imagery, language, and the like-may be simultaneously operating, and not necessarily in service of the same outcomes), TCD still would not measure the cognitive operation itself. TCD does not even provide a direct measure of the neural activity that corresponds to the cognitive operations. Rather, TCD yield a measure of the speed of blood flow, which has been shown to be a function of neural activity somewhere in the perfusion zone, which has been shown to increase as mental activity increases. Further, TCD is spatially limited to the three broad, overlapping perfusion areas in each hemisphere that are served by the cerebral arteries. The skeptic might argue that examining the neurocognitive basis of behavior with TCD is like trying to measure the quality of an artist's work by recording patterns of carpet wear in the museum (although at least TCD has the temporal resolution advantage of rapid changes, which would be difficult to capture in the cynical analogy).

Notwithstanding these accurate criticisms, we contend that TCD does indeed have value for cognitive neuroscience, and will point to studies from the literature and from our laboratory that illustrate these benefits. As an overview, we suggest the following uses for TCD from the perspective of cognitive science:

a. Hemispheric differences: A wide range of methods have been used to study the differences between the left and right cerebral hemispheres. Although the popular conceptions of "left brain / right brain" (to borrow the title of Springer \& Deutsch's excellent 2001 review of the literature) fail to do justice to the unity, interhemispheric communication and coordination, and plasticity of the brain, it is undeniable that the cerebral hemispheres differ reliably in structural and functional ways. The popular caricature of the left hemisphere as specializing in verbal, analytic, and sequential processing, with the right hemisphere as the home of visuospatial, holistic, parallel processing is at minimum over-simplified, and in many ways simply incorrect. Nevertheless, the localization to the left hemisphere of neural structures involved with language production and comprehension, at least for most right-handed participants, anchors the search for functional cerebral asymmetries that serve to enhance the cognitive competencies of animals (particularly humans) with large, highly encephalized, bilateral brains. The methods for examining these structural and functional asymmetries include all those subsumed under the label of neuroimaging (e.g., fMRI, EEG) as well as the clinical explorations of individuals with brain damage, split-brains (surgical severing of the corpus collosum, for example as an extreme treatment for epilepsy), and so forth. Additionally, a number of noninvasive behavioral paradigms have been used successfully to examine functional cerebral asymmetries, including divided visual-field paradigms and dichotic-listening paradigms which 
capitalize on the contralateral organization of perceptual-motor processing (e.g., the left hemisphere receives first input from the right side of visual space and from the right ear and controls motor function on the left side of the body, and vice versa). Attempts to measure functional cerebral asymmetries with psychophysiological measures such as tympanic-membrane temperature (e.g., Helton, 2010; Hopkins \& Fowler, 1998) have also revealed interesting differences. TCD is arguably a more direct and more sensitive measure of task-related brain activity than is tempanic-membrane temperature, and in any case is a complementary measure in a field where converging evidence from behavioral, psychophysiological, and clinical data are important. Although there is certainly localization of cognitive functions without lateralization, hemispheric asymmetries in cognition do provide broad evidence about localization, which in turn may inform theoretical dissociations. For example, the theoretical dissociation between vigilance (sustained attention) and concentration (executive attention) as components of the construct "attention" has been supported with a variety of neuroimaging and cognitive paradigms (e.g., Posner \& Rothbart, 2007) - including TCD, which indicates a right-hemisphere advantage for the control of vigilance (Warm, Matthews, \& Parasuraman, 2009).

b. Individual and group differences: Even if TCD provided no information about localization, it provides a behaviorally relevant psychophysiological measure that shows task-related variability that needs to be explained. There are many examples of insights from psychophysical measures that complement, and in many cases that are more sensitive than, overt behavioral responses. Tiny movements of facial muscles, unobservable to the naked eye but recordable through electromyography reflect implicit attitudes about social-category membership (e.g., Vanman, Saltz, Nathan, \& Warren, 2004). Variations in skin conductance reveal the contributions of affective states in judgment and decision making (e.g., Naqvi \& Bechara, 2006). Occulomotor measures (eye gaze and pupil dilation) reflect the strategy and intensity of cognitive processing in reading and other operations (e.g., Just \& Carpenter, 1995). Similarly, TCD provides value to cognitive neuroscience as another measure in which individuals and groups differ, and thus another potential predictor of the massive amount of unexplained variance that characterizes behavior. As will be discussed below, this measure is being used already in research on the cognitive differences between various groups, including females/males, children/adults, old/young, clinically diagnosed/control, and so forth.

c. Third, CBFv from TCD has value as a marker for mental effort. Vingerhoets \& Luppens (2001) argued this point specifically (ironically in a study designed to show lateralization effects, which were largely absent in the results). Within a task, within a group, even within a participant, variations in workload or mental effort can alter performance and/or create error in measures of response latency, response accuracy, response topography, and so forth. Changes in CBFv may provide important insights into the intensity of mental activity, even in the absence of overt behavior to indicate stimulus processing. Many theorists have differentiated between two sources or types of cognitive control, in which some behaviors are determined automatically, reactively, through stimulus control or contention scheduling, whereas other behaviors are controlled, proactive, executively or willfully controlled (e.g., Banich, 2009; Braver, Paxton, Locke, \& Barch, 2009; Cooper \& Shallice, 2000; Hickey, van Zoest, \& Theeuwes, 2010; Norman \& Shallice, 1986; Schneider \& Chein, 2003; Washburn \& Taglialatela, 
2006). Both automatic and controlled processing involves neural activity, of course, but by definition, automaticity is not cognitively demanding. Thus, one way of distinguish processing that is controlled, willful, and executive in nature (ultimately with the goal of understanding each of these terms in a way that does not require a homunculus) is to look for evidence of mental effort. The changes in CBFv measured by TCD promise to be one such measure. These data would complement other indicators of executive control versus contention scheduling (e.g., another criterion of automaticity is that it is fast, and so chronometric measures have been used to suggest when mental processing is controlled and proactive versus automatic and reactive).

\section{Cognitive task-related changes in CBFv}

As further evidence of the value of TCD for cognitive neuroscience, consider the studies that currently appear in the literature. Researchers have examined TCD-assessed changes in CBFv as a function of a wide range of cognitive activities. Table 1 shows how the number of PsycINFO-registered publications in which TCD was used has increased over the last three decades, suggesting that the paradigm is currently enjoying a surge in popularity (although it remains the case that most TCD publications are written by scholars in Europe). For comparison purposes, similar publication counts are provided for another relatively inexpensive new transcranial neuroimaging technique, transcranial magnetic stimulation (TMS). For TMS, an electromagnetic coil is used to stimulate neural firing, effectively creating a temporary functional "lesion" that disappears when the magnetic stimulation abates (Walsh \& Pascual-Leone, 2005). Like TCD, TMS is noninvasive as the magnetic stimulation passes painlessly and harmlessly through bone and other tissue. Note that the rate of TMS publications has also increased dramatically in recent years; indeed, the rate of growth of cognitive neuroscience studies using TMS far exceeds those using TCD. Nevertheless, neither transcranial technique is being used and published at levels comparable to, or consistent with the growth characteristic of, MRI studies over this same period. (Of course, these publications referenced by PsycINFO reflect only a fraction of the total publications in which TCD, TMS, and MRI are used. For example, MEDLINE shows over 1,300 publications since 2007 using TCD. Some of these surely document CBFv effects of cognitive activity, just like the PsycINFO-referenced articles reviewed in the present chapter; however, it seems reasonable to suppose that most researchers who use TCD to study cognition would select a psychology-related outlet for the publication.)

\begin{tabular}{|c|c|c|c|c|c|c|}
\hline & $\mathbf{1 9 8 1 - 1 9 8 6}$ & $\mathbf{1 9 8 7 - 1 9 9 1}$ & $\mathbf{1 9 9 2 - 1 9 9 6}$ & $\mathbf{1 9 9 7 - 2 0 0 1}$ & $\mathbf{2 0 0 2 - 2 0 0 6}$ & $\mathbf{2 0 0 7 - 2 0 1 1}$ \\
\hline TCD & 0 & 15 & 33 & 61 & 95 & 274 \\
\hline TMS & 0 & 9 & 61 & 380 & 1074 & 2042 \\
\hline MRI & 66 & 533 & 1511 & 3153 & 6822 & 16526 \\
\hline
\end{tabular}

Table 1. PsycINFO publications for three neuroimaging methods, by 5-year periods

\subsection{Hemispheric differences in CBFv}

As Stroobant and Vingerhoets (2000) noted in their review, the primary question in most TCD studies is, "How do the cerebral hemispheres differ with respect to cognitive processing?" Given that the spatial resolution of TCD is limited to the perfusion areas of the cortical arteries being measured, it is difficult to do neuroimaging studies that require 
localization more specific than broad functional hemispheric asymmetries. (By measuring anterior versus posterior cerebral arteries, it is also possible to examine some general differences between lobes within each hemisphere, but the lateralization studies constitute the preponderance of the TCD literature.) Accordingly, Stroobant and Vingerhoets reviewed clear $\mathrm{CBFv}$ evidence for left-hemisphere specialization for processing language-related stimuli, and some less-consistent evidence from TCD studies of right-hemisphere advantages for visuospatial processing.

Lateralization studies since 1999 show similar patterns of results, but not without exceptions. For example, Kratch, Chen, and Hartje (2006) assessed functional cerebral asymmetries using TCD as well as a divided visual field paradigm. Although both measures showed lateralization effects for lexical-decision performance, the effects were not reliably correlated across paradigms. This task showed the predicted left-hemisphere advantage in the divided visual field procedure, but produced faster right-hemisphere than lefthemisphere CBFv. Similarly, Knetch and colleagues (2001) focused on participants with atypical, right-hemisphere specialization for language, as revealed by TCD, but did not find these participants to be deficient in linguistic performance on a variety of measures. Conversely, Szirmai and colleagues (2005) examined lateralization for verbal fluency and mental arithmetic tasks using both TCD and electroencephalography measures, and found significant correlations, at least for verbal fluency.

In our laboratory, we have also examined functional cerebral asymmetries in cognitive performance using a variety of paradigms, including TCD. In studies of individual differences in attention skills, we required participants to monitor a scene and to make rapid and accurate shoot/don't-shoot responses to target/nontarget stimuli (Schultz, Matthews, Warm \& Washburn, 2009). The scene was projected on a wall so as to fill the visual field, and participants used a laser-modified handgun to respond to infrequent target images that appeared during a 36-minute vigil (see Figure 1). CBFv was bilaterally recorded throughout the vigil, and during a resting baseline period, to determine whether TCD measures would show vigilance decrements corresponding to the changes in task performance (response time, target detection hits and misses, marksmanship accuracy) as a function of time-ontask. As will be discussed below, systematic vigilance effects were observed. Of relevance to the present discussion, we also reported significant hemispheric differences for this task (albeit in the opposite direction from what was predicted). Parallel vigilance decrements were obtained for both cerebral hemispheres, but mean $\mathrm{CBFv}$ was consistently faster (relative to baseline) in the left hemisphere than in the right hemisphere, across the vigil.

In follow-up studies (e.g., Schultz, Phillips, \& Washburn, 2010), we further investigated this cerebral asymmetry. The right-hemisphere advantage was unexpected, given the sustainedattention demands of this shoot/don't-shoot task. A speeded threat/nonthreat determination was required of participants every 3 seconds on average (interstimulus interval was randomized between 1 and 5 seconds), but only $25 \%$ of the stimuli required a "shoot" response. Given the long watchkeeping period and indeed the clear vigilance decrements that were observed across this period in response latency, decision accuracy (hits, misses, false alarms), and marksmanship accuracy, we expected to see evidence in the TCD data for a right-hemisphere specialization in vigilance. This prediction was based on findings that right frontal regions and right parietal cortex serve, along with the locus coeruleus, as a brain network for alertness or vigilance (Posner \& Raichle, 1997; Warm et al., 2009). Our 
finding of elevated $\mathrm{CBFv}$ in the left hemisphere compared to the right hemisphere-an advantage that was stable across the vigil - was surprising.

The stability of the hemispheric difference in $\mathrm{CBFv}$ across the watchperiod provides one clue toward unpacking this curious result. In earlier TCD studies of vigilance (Helton et al, 2007; Hitchcock et al., 2003; Warm et al., 2009), the right-hemisphere advantage became evident as time-on-task increased. Early in the vigil, mean CBFv (relative to resting baseline) was comparable in the two hemispheres, but as the demands on sustaining attention increased over time, a cerebral asymmetry emerged reflecting activity in the right cerebral hemisphere. This consistent and intuitive finding is not what was observed in the TCD data of the Schultz and collaborators (2009) study. In our task, faster CBFv in the left hemisphere was observed even in the first quarter of the watchperiod. Indeed, in follow-up analyses we noted that the left-hemisphere advantage in CBFv is statistically significant within the very first minute of the task (Schultz, Phillips, \& Washburn, 2010). This is presumably before vigilance would be required, or at least when the demands on sustained attention should be minimal. That this level of asymmetry was then stable throughout the vigil suggests that our left-hemisphere advantage for this task was not indicative of the lateralization of vigilance,
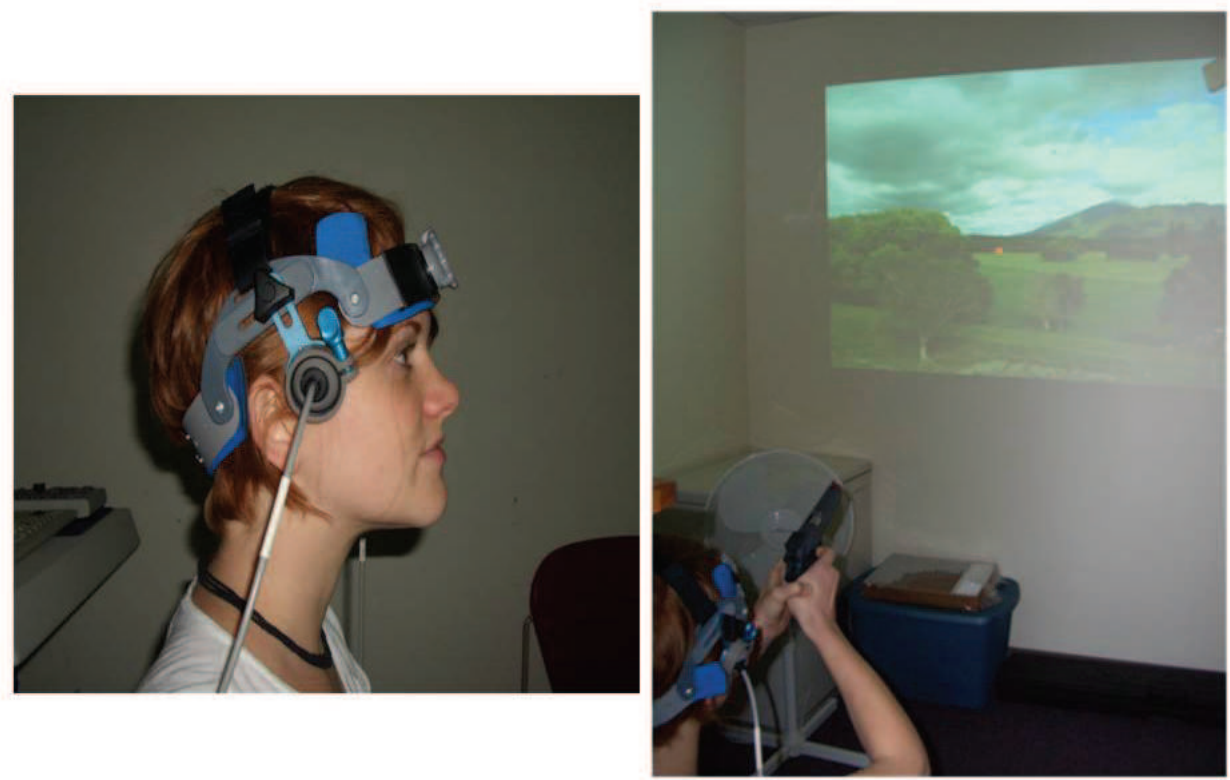

Fig. 1. Apparatus used in the Schultz et al. (2009) study. Left: The Transcranial Doppler Sonography transducers positioned at the right and left (not pictured) transtemporal window for recording changes in cerebral blood flow velocity through the middle cerebral artery of each hemisphere. The two 2-MHz transducers are connected to a Companion III TCD system (Nicolet/EME, Madison, WI), which uses Fast Fourier analysis to transform the signals and displays mean $\mathrm{CBFv}$ for each heartbeat-cycle envelope. Right: The participant uses a laser-modified handgun to respond to computer-generated stimuli projected on a wall. Shots were automatically detected and recorded (time, location) by LaserShot (Stafford, TX) hardware and software 
but rather a lateralization of the shoot/don't-shoot judgments themselves that whelmed any right-hemisphere localization of sustained attention. In our study, the encoding and discrimination of threat/nonthreat images and the motor-preparation/aim/fire components of responding showed a left-hemisphere lateralization. With respect to this conclusion, it is important to note that all of our participants were right handed (as assessed by self-report); thus, it remains to be determined the proportion of this left-hemisphere advantage that is directly related to motor versus cognitive factors.

\subsection{Group differences in CBFv}

Stroobert and Vingerhoets (2000) reviewed the literature on cerebral hemodymanic effects of cognitive task performance. The tasks included in this review span a wide range, including simple motor tasks, linguistic tasks (e.g., reading, synonyms, syntax, word association, sentence completion, verbal fluency), visuospatial tasks (e.g., faces, designs, imagination, picture matching, cube comparison, mental rotation), numeric tasks (e.g., multiplication, dot estimation), and other tasks (e.g., music, sorting, vibratory stimulation, passive viewing). Their review summarized major themes of research and findings to that date. For example, they summarized TCD studies on the effects of gender, age, and handedness on CBFv and lateralization (i.e., hemispheric differences) in CBFv. They noted that blood flow velocity declines in older adults, as does lateralization. Where gender differences were reported, females produced higher CBFv. Handedness effects on lateralization were also reported, with consistent left-hemisphere advantages for the processing of linguistic stimuli among right-handed participants. The pattern of cerebral asymmetries in $\mathrm{CBFv}$ were less clear for left-handed participants (as is typically found using other paradigms as well).

Studies along these lines have continued in the years since the Stroobant and Vingerhoets (2000) review. For example, Bracco and colleagues (2011) used TCD with a memory task, and found that both males and females showed material-specific lateralization effects (e.g., memory for verbal material was lateralized to the left hemisphere, whereas memory for visuospatial material was right-hemisphere lateralized), although the lateralization of nonverbalizable material was attenuated with aging. Sorond and colleagues (2008) also found effects of aging on TCD values as participants performed word-stem completion and visual-search tasks. CBFv increase differentially in the anterior and posterior cerebral arteries for the elderly compared to the young-adult participants.

Although the Bracco et al. (2011) study reported no gender differences in CBFv, Walter, Roberts and Brownlow (2000) reported gender differences in CBFv (women faster than men) and lateralization patterns during performance of visuospatial tasks (mental rotation, visualizing). Similarly, Njemanze (2005) observed different hemispheric advantages for females and males solving the Raven's Progressive Matrices test, with females showing a left-hemisphere advantage and males showing a right-hemisphere effect. Schuepbach and colleagues (2009) used the Wisconson Card Sorting Test, and found linkages between the mental slowing that occurs during set-shifting and increases in $\mathrm{CBFv}$, but only for females. Misteli and colleagues (2011) tested participants with a different executive functioning task (Trail-making) and found a similar gender difference in TCD data, with females showing a lateralization shift that was synchronized to a frequency peak in middle cerebral artery CBFv. 
There have been many studies in which TCD was collected as part of comparisons between groups formed on the basis of clinical diagnoses. Cognitive testing has been complemented with TCD measures of CBFv to study the executive-function skills (Kral \& Brown, 2004; Kral et al., 2003) and language functioning (Sanchez, Schatz, \& Roberts, 2010) of children with sickle cell disease; to examine the executive-function deficits, particularly those involved in planning, associated with schizophrenia (Feldmann et al., 2006; Schuepback, Weber, Kawohl, \& Hell, 2007); in the attention skills of participants with and without hypotension (Duschek \& Schandry, 2004); in elderly adults with versus without depression (Tiemeier et al., 2002); to examine executive functioning in patients with Huntington's disease versus healthy controls (Deckel, Cohen, \& Duckrow, 1998); and in the mental activity patterns of healthy individuals versus individuals recovering from stroke versus individuals who have shown no recovery from stroke (Bragoni et al., 2000). The results of these patterns are not as simple as "clinical conditions are associated with slower CBFv" - although that is what one sees for planning by individuals with schizophrenia compared to healthy controls (Feldmann et al., 2006), for depressed individuals compared to their nondepressed cohort (Tiemeier et al., 2002), and for individuals with Huntington's disease compared to healthy individuals (Deckel et al., 1998). Conversely, poorer cognitive performance by children with sickle cell disease is associated with abnormally high CBFv (Krall and colleagues, 2003, 2004; Sanchez et al., 2010). Another pattern of results is apparent in several studies, where CBFv is comparable between the comparison groups, but the clinical population shows less modulation or lateralization of blood flow, compared to healthy controls. This result was reported for individuals with schizophrenia (Schuepback et al., 2007) and for hypotensive compared to normotensive patients (Duschek \& Schandry, 2004).

As was discussed above, one drawback to the TCD method is that there are participants for whom it is difficult or impossible to acquire CBFv readings from the middle cerebral artery on both sides of the brain. For many participants, bilateral measurement of this artery is easy to acquire, whereas even highly skilled experimenters are unable to sonate one or both arteries for other participants. We were interested in whether there are cognitive differences to correspond to these groups (i.e., participants from whom left+right hemisphere signals were obtained, compared to participants with left-hemisphere readings only, those with right-hemisphere readings, and those for whom neither hemisphere could be reliably sonated. Each of 540 undergraduate volunteers were tested on a shoot/don't-shoot task like the one described above (Schultz et al., 2009). For $47 \%$ of these volunteers, bilateral recording was possible. For $17 \%$ of the sample, only the right hemisphere could be sonated, whereas $5 \%$ of the participants contributed CBFv data only for the left hemisphere. The remaining $31 \%$ of the participants completed the shoot/don't-shoot task wearing the TCD apparatus, but a reliable signal for the cerebral artery of interest could not be located on either side of the brain.

We examined performance measures to determine whether these group differences were meaningful and diagnostic in any way. Table 2 summarizes shoot/don't-shoot performance for these four groups of participants. No differences were observed between the groups in decision accuracy (i.e., hit rate or false-alarm rate) or shot latency. For marksmanship error, there was a significant difference, which post doc analyses revealed to be the result of significantly $(p<.02)$ poorer marksmanship by the group in which no TCD signal was obtained, compared to the other three groups. Participants for whom we were unable to locate a stable middle-cerebral-artery signal in either hemisphere produced shots about $15 \%$ 
less accurate (further from the target) than the other participants. Perhaps this difference in marksmanship was a function, at least in part, of the relatively longer experimental sessions for these participants (i.e., the experimenters would try as long as possible to find a stable signal, and thus participants without a signal spent more time on average in the pre-task phase of the study than did the other volunteers). In any case, this difference seems fairly inconsequential in comparison to the more general finding: The subset of the sample for which good, bilateral recording was possible appears to be representative of the entire pool of volunteers, at least with respect to performance measures on this shoot/don't-shoot task. We see little reason to conclude that there is anything worrisome or diagnostic in this particular between-groups variable.

\begin{tabular}{|c|c|c|c|c|}
\hline & $\begin{array}{c}\text { Hit } \\
\text { Rate }\end{array}$ & $\begin{array}{c}\text { False-alarm } \\
\text { Rate }\end{array}$ & $\begin{array}{c}\text { Shot } \\
\text { Latency }\end{array}$ & $\begin{array}{c}\text { Marksmanship } \\
\text { error }\end{array}$ \\
\hline Both hemispheres & $86 \%$ & $1 \%$ & $987 \mathrm{msec}$ & $2.79 \mathrm{~cm}$ \\
\hline Left hemisphere only & $83 \%$ & $1 \%$ & $1035 \mathrm{msec}$ & $2.56 \mathrm{~cm}$ \\
\hline Right hemisphere only & $86 \%$ & $1 \%$ & $994 \mathrm{msec}$ & $2.80 \mathrm{~cm}$ \\
\hline Neither hemisphere & $86 \%$ & $1 \%$ & $982 \mathrm{msec}$ & $3.20 \mathrm{~cm}$ \\
\hline
\end{tabular}

Table 2. Shoot/don't-shoot decision making, decision latency, and marksmanship accuracy as a function of groups formed on the basis of whether we were able to obtain stable TCD signals from the left and right cerebral hemispheres

One can also compare cognitive-task performance and CBFv measures between groups that are formed on the basis of performance on some criterial task or measure. Researchers who study working-memory capacity, for example, have been using this extreme-groups design strategy to reveal the cognitive and neural differences between individuals with high-span versus low-span memories (e.g., Chein, Moore \& Conway, 2011; Kleider, Parrot, \& King, 2010; Osaka et al., 2004; Unsworth \& Engle, 2008) - although it appears that no one to date has compared CBFv of span-based groups using TCD. Duschek, Schuepbach and Schandry (2008) did however compare CBFv values derived from TCD between two groups that were formed on the basis of performance on a simple reaction-time task with an auditory attention cue. High-performance participants were characterized by greater increases in bilateral $\mathrm{CBFv}$ than low-performance participants - a difference that was significant even two seconds after the alerting tone (i.e., three seconds before presentation of the visual stimulus that required a response).

In our laboratory, we routinely test participants on a battery of attention-related tasks (the Assessment Software for Attention Profiles or ASAP battery), and subsequently form and compare groups on the basis of these attention profiles (e.g., Washburn, Smith \& Taglialatela, 2005). The ASAP battery was constructed to include tasks that load on each component factor or dimension of attention (see Table 3). For example, previous factor analyses of the ASAP battery show that performance on incongruent Stroop trials clusters together with performance on a stop-signal inhibition task and response times on the "executive" component of the Attention Network Test (incongruent - congruent flanker stimuli; see Fan et al., 2005). Quartile splits were used to divide participants into groups, so that the top- and bottom-quartile-groups might be compared with respect to $\mathrm{CBFv}$. 


\begin{tabular}{|c|c|c|c|c|}
\hline $\begin{array}{c}\text { Factor or Dimension } \\
\text { (with alternate } \\
\text { names from the } \\
\text { literature) }\end{array}$ & $\begin{array}{c}\text { ASAP tasks } \\
\text { (determined by } \\
\text { prior factor } \\
\text { analyses) }\end{array}$ & $\begin{array}{c}\text { Left hemisphere } \\
\text { mean CBFv, } \\
\text { relative to resting } \\
\text { baseline }\end{array}$ & $\begin{array}{c}\text { Right hemisphere } \\
\text { mean CBFv, } \\
\text { relative to resting } \\
\text { baseline }\end{array}$ & $p$ \\
\hline $\begin{array}{c}\text { Attention focusing } \\
\text { (executive attention, } \\
\text { concentration) }\end{array}$ & $\begin{array}{c}\text { Stroop, Stop- } \\
\text { signal, ANT- } \\
\text { executive }\end{array}$ & $1.967(0.28)$ & $1.533(0.22)$ & $p<.01$ \\
\hline $\begin{array}{c}\text { Attention scanning } \\
\text { (orienting, shifting, } \\
\text { selection) }\end{array}$ & $\begin{array}{c}\text { Cue task, } \\
\text { Antisaccade task, } \\
\text { Visual Search }\end{array}$ & $-1.202(0.77)$ & $-1.032(1.06)$ & $p>.10$ \\
\hline $\begin{array}{c}\text { Attention sustaining } \\
\text { (alerting, vigilance) }\end{array}$ & $\begin{array}{c}\text { Continuous } \\
\text { Performance } \\
\text { Task, ANT- } \\
\text { alerting }\end{array}$ & $0.150(0.78)$ & $0.75(0.67)$ & $p<.05$ \\
\hline
\end{tabular}

Table 3. Mean CBFv values (expressed relative to resting baseline, such that positive numbers indicate that blood flow had increased compared to baseline, whereas negative numbers denote slower-than-baseline blood flow) and standard deviations by cerebral hemisphere and attention-factor

A similar extreme-groups strategy was used to analyze task performance described by Schultz et al. (2009), described above. Participants in the shoot/don't-shoot study were grouped according to quartiles, based on response latency and marksmanship accuracy. That is, we grouped the fastest shooters together in a group, using only those trials in which the stimulus was in fact a threat or "shoot" target, and the slowest shooters together in another group. Similarly, we grouped the most accurate shooters-again, not in terms of decision accuracy, as each of these responses was a "hit" in the sense of being a "shoot" response to a threat stimulus, but rather in terms of marksmanship accuracy, measured by the distance between the target and the location of the fired laser shot. Participants with least-accurate marksmanship were grouped together for comparison. Mean CBFv values were then computed from the middle cerebral artery of each hemisphere for each of these groups. Figure 2 summarizes the results of these analyses.

When the fastest-shooters were compared to the slowest-shooters group, a significant interaction was observed. The fastest shooters were characterized by a significant lefthemisphere advantage in $\mathrm{CBFv}$. For the slowest-shooter group, $\mathrm{CBFv}$ was slightly but not significantly faster in the right hemisphere. This interaction was not seen in the extremegroups analysis based on marksmanship accuracy, where both groups displayed leftlateralized CBFv for the task (as was seen for the overall analysis of all participants).

These same data also illustrate how TCD has been used to provide an individual-differences measure for psychometric studies of cognition. Recall the nature of the laboratory task discussed here: A participant is required to monitor a naturalistic scene and to make repeated threat/nonthreat (shoot/don't-shoot) judgments on the basis of stimulus appearance. The task was designed to mimic some of the elements of the real-life task performed by security officers, sentries, or police officers, or soldiers on a peacekeeping mission. These individuals must maintain vigilant attention across time, while they make 

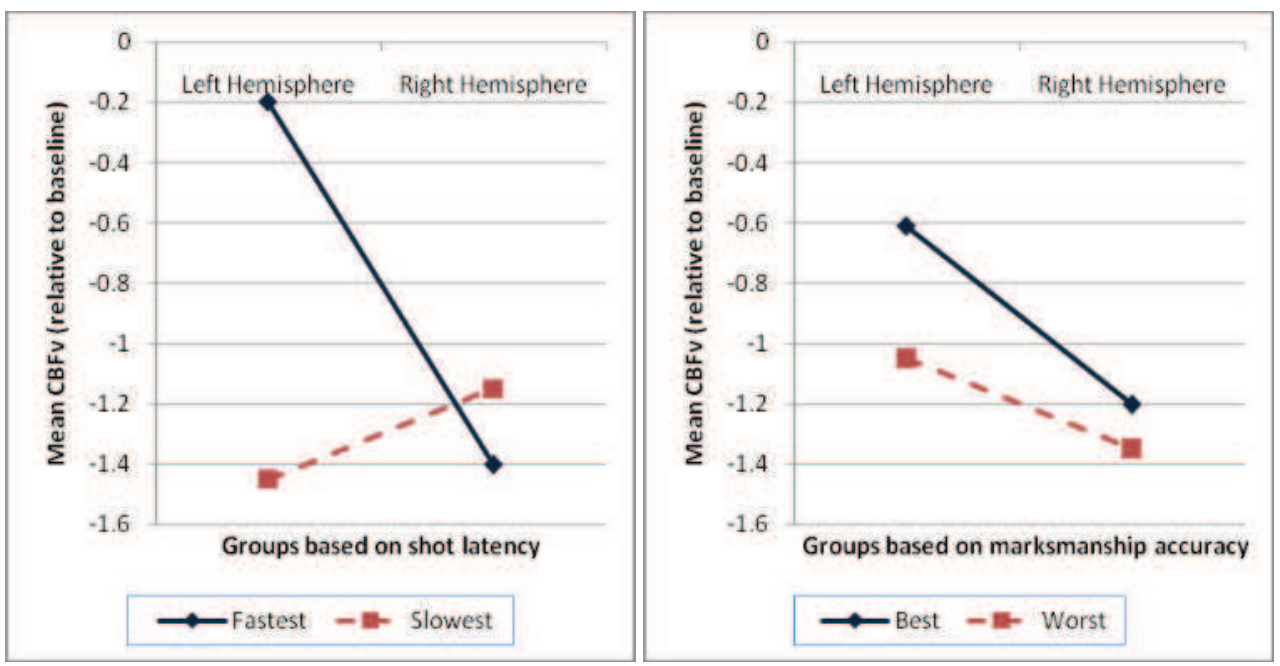

Fig. 2. Comparison of mean $\mathrm{CBFv}$, relative to baseline, between performance-based groups in the shoot/don't-shoot task. Left: Groups formed on the basis of shot latency. Right: Groups formed on the basis of marksmanship accuracy

threat/nonthreat judgments about events around them. Threatening events are rare in most cases, but the life-or-death costs of making a poor decision (e.g., being too slow to shoot if there is a threat, or too quick to shoot at what turns out to be a nonthreat stimulus) are severe. Ideally, one would want a way of monitoring vigilance so that individuals faced with these critical decisions could be maximally attentive, or perhaps so interventions could be introduced at points when vigilance is flagging. This was the rationale behind the shoot/don't-shoot study designed by Schultz and colleagues (2009), who attempted to use measures available prior to a "shoot" response to predict the speed with which participants would respond to threat stimuli.

We found that response latency to a threat stimulus was significantly predicted by the participant's response time on the previous "shoot" trial, irrespective of how long it had been since that response $\left(R^{2}=.098, p<01\right)$. By adding time-on-task to the regression equation, one could significantly increase the proportion of variance accounted for $\left(\Delta R^{2}=\right.$ $.024, p<01)$. One could significantly augment this prediction further by adding a measure of $\mathrm{CBFv}$ in the left hemisphere. In fact, the prediction of shot latency was improved by $\mathrm{CBFv}$ values from the left hemisphere even if those values were selected as far back as 18 seconds before the threat image appeared on the screen $\left(\Delta R^{2}=.015, p<01\right)$. Overall, we were able to account for $13 \%$ of the variance in shot latency by knowing how quickly the participant tends to shoot when the response is appropriate, how long the participant has been required to remain vigilant on the task, and how rapidly blood is flowing through the middle cerebral artery of the left hemisphere. Of course, $13 \%$ of explained variability means that $87 \%$ of the variability remains unexplained, and further investigation with additional predictors is required to make this statistically significant prediction more practical. For the present discussion however, the fact that $\mathrm{CBFv}$ measures reliably augment the prediction of 
task performance is sufficient to illustrate the ways that TCD has been, and can be, used in the study of individual differences.

The Matthews and colleagues, 2010, study discussed below also illustrates this use of TCD as a diagnostic tool. Further, Warm and colleagues (2009) reported that TCD measures may be useful as a selection tool for assigning personnel to vigilance duties. Reporting on the results of a study in their laboratory by Reinerman and collaborators (2006), these authors argue that $\mathrm{CBFv}$ changes during a battery of demanding tasks, combined with self-report measures of task engagement, significantly predicted subsequent vigilance performance. As was discussed above, these measures combined to account for $13 \%$ of the variance in subsequent vigilance performance.

\subsection{TCD studies of attention and executive function}

As summarized above and by Stroobant and Vingerhoets (2000), many researchers designing TCD studies over the last three decades have included explicitly verbal or visuospatial tasks, primarily to study lateralization effects (e.g., Dorst et al., 2008; Haag et al., 2010; Horton-Lambirth \& Roberts, 1998; Lust, Geuze, Groothuis, and Bouma, 2010). A more recent development in the TCD literature is the increase in tasks designed to measure attention and closely related processes like inhibition, set-switching, planning, and maintaining/monitoring (i.e., the so-called "executive functions" or EF; see Banich, 2009; Barkley \& Murphy, 2011; Latzman \& Markon, 2010; Lyon \& Krasnegor, 2005; Wiebe et al., 2011). Discussed already are recent studies in which popular attention and EF tasks like Wisconsin Card Sort, Trail-making, Stroop task, and Visual Search were used, albeit those discussions were focused on the group (e.g., gender) differences that were revealed in these tasks and in task-relevant changes in CBFv. Beyond this use of attention and EF tasks as potential measures on which differences may seen across genders, ages, diagnostic categories, and so forth, TCD may contribute to understanding of cognitive control and the ways that mental effort is allocated (or in the instances of cognitive disorders, is not allocated or controlled) to produce goal-appropriate performance.

One of the significant developments in the TCD field over the last decade is the emergence of a productive research team at the University of Cincinnati, anchored by Gerald Matthews, Joel Warm, and their collaborators. This research team studies cognition in applied settings, with particular attention to the relation between individual differences in cognitive and personality profiles and performance in human-machine (human factors) environments. For these scientists, with their backgrounds in research on topics like mental workload, stress states, and vigilance, TCD provided an ideal tool for continuous and noninvasive assay of cognitive activity. To quote the title of one of their publications (Warm, Parasuraman \& Matthews, 2008), "vigilance requires hard mental work and is stressful" and it seemed reasonable to suppose that TCD would provide a way to As was discussed above, these researchers quickly established a literature on the cerebral hemodynamics of vigilance, documenting the decline of $\mathrm{CBFv}$ as a function of time-on-task that reflects the gradual shift from controlled toward automatic, lessattentive processing across the watchperiod (Helton et al., 2007; Schultz et al., 2009; Warm \& Parasuraman, 2007; Warm et al., 2009). They also demonstrated that salient signals from 
the environment in the form of automation cuing of potential threats during the vigil can attenuate this decline in $\mathrm{CBFv}$ and mitigate the vigilance decrement (Hitchcock et al., 2003).

Matthews and colleagues (2010) used TCD as part of a battery of personality, psychophysiological, stress-state, and cognitive measures to predict vigilance performance of two groups of participants, each completing one of two vigilance tasks. As has been demonstrated consistently across many studies, CBFv declined across the watchperiod, and correlated with decrements in performance measures. Interestingly, $\mathrm{CBFv}$ was faster in the left hemisphere than the right hemisphere in this study, as had been reported by Schultz and collaborators (2009). Indeed, the pattern of performance from a sensory vigilance task in which participants monitored a display for 36 minutes and made judgments about a series of stimuli that depicted either "safe" or "threat" air-traffic situations. In contrast however, the decline in CFBv was more precipitous for the TCD data from the right hemisphere than from the left hemisphere for the vigilance task that required participants to retain and manipulate information in memory across the 36-minute test. For both vigilance tasks, $\mathrm{CBFv}$ was comparable in the blateral middle cerebral arteries at the outset of the vigil, but for the more cognitively demanding task the degree of lateralization was modulated across the vigil.

Matthews and colleagues (2010) used structural equation modeling to test a series of latent-factor models of effortful, sustained attention in tasks that require vigilance. The model that successfully fit the data included latent variables representing task engagement, derived from a self-report instrument administered during a pre-test baseline period and after the participants performed several cognitive tasks. The model also included CBFv, which appeared to index another resource-related energizing function, such as a psychophysiological proxy of mental effort. The addition of other predictors did not substantively improve the fit of this model, which accounted for $19 \%$ of the variance in performance on the the sensory (air-traffic control) vigilance task, and $18 \%$ of the variability in the cognitively demanding (working memory) vigilance task.

Of course, the hemodynamic correlates of cognitive control have been investigated by other researchers as well. In several studies, Duschek, Schuepbach, and colleagues provided elegant evidence for TCD as a tool for measuring the bilateral increases in CBFv as participants prepare and process task-relevant information (Duschek, Schuepbach \& Schandry, 2008; Schuepbach, Boeker, Duschek \& Hell, 2007). In each study, the authors traced the time-course of $\mathrm{CBFv}$ changes, and linked those changes to pre-response cognitive processes such as preparatory attention and planning, respectively. Similarly, Schuepbach and collaborators (2004) examined the effects of set-maintenance and set-switching on CBFv in the anterior and middle cerebral arteries of each hemisphere, and found significant increases in peak $\mathrm{CBFv}$ in the anterior perfusion region. In In another study from this general research team, Duschek, Werner, Kapan, and Reyes del Paso (2008) used TCD and various other instruments to study psychophysiological changes during mental arithmetic, and attributed the observed left-hemisphere increase in $\mathrm{CBFv}$ to the cognitive effort required to perform the "cross sum" task (i.e., to add four single-digit numbers, and then to add the digits of the result). In our laboratory, we also used a mental arithmetic task as a distractor condition during a vigilance task, to show that the hemodynamic and behavioral 
patterns produced by inattention are discernable from the hemodynamic and performance patterns produced by distraction (i.e., of covertly switching attention to task-irrelevant processing; Washburn \& Schultz, 2009).

\section{Summary}

Despite the limitations of the TCD paradigm, evidence is growing that it is a valuable tool in the study of brain-behavior relations that constitute cognitive competence. Many questions remain about the structural and functional differences between the cerebral hemispheres, and how those differences interact with grouping variables like gender, age, and diagnostic category; however, the present authors are most excited about the potential for using TCD to provide a measure of mental effort and cognitive control. Recent studies from scholars on both sides of the Atlantic Ocean illustrate the several ways that this noninvasive paradigm for the continuous, bilateral measurement of $\mathrm{CBFv}$ can inform our understanding of mental effort-providing in some instances converging evidence that can be integrated with behavioral observations (e.g., response latencies or accuracy levels), and in other cases a method for measuring the intensity of cognitive processing even in the absence of corresponding overt behavior.

\section{Acknowledgments}

The authors acknowledge the assistance of Gerald Matthews and Joel Warm in establishing our TCD laboratory, and the assistance of Jared Taglialagela, Frances James and R. Thompson Putney in some of the tasks reviewed here. This research and development, and preparation of this chapter were supported by grants and contracts from the National Institute of Child Health and Human Development (HD-060563), the United States Army Medical Research and Materiel Command (W81XWH-04-C-0002), and by Georgia State University. For more information, contact David A. Washburn, Department of Psychology, Georgia State University, Box 5010, Atlanta, GA 30302-5010, USA or dwashburn@gsu.edu.

\section{References}

Aaslid, R. (1987). Visually evoked dynamic blood flow response of the human cerebral circulation. Stroke 18: 771-775.

Aaslid, R., Markwalder, T. M., and Nornes, H. (1982). Noninvasive transcranial Doppler ultrasound recording of flow velocity in basal cerebral arteries. Journal of Neurosurgery 57: 769-774.

Banich, M. T. (2009). Executive Function: The Search for an Integrated Account. Current Directions in Psychological Science (Wiley-Blackwell), 18(2), 89-94. doi:10.1111/j.1467-8721.2009.01615.x

Barkley, R. A., \& Murphy, K. R. (2011). The Nature of Executive Function (EF) Deficits in Daily Life Activities in Adults with ADHD and Their Relationship to Performance on EF Tests. Journal of Psychopathology \& Behavioral Assessment, 33(2), 137-158. doi:10.1007/s10862-011-9217-x 
Bragoni, M. M., Caltagirone, C. C., Troisi, E. E., Matteis, M. M., Vernieri, F. F., \& Silvestrini, M. M. (2000). Correlation of cerebral hemodynamic changes during mental activity and recovery after stroke. Neurology, 55(1), 35-40.

Braver, T. S., Paxton, J. L., Locke, H. S., \& Barch, D. M. (2009). Flexible neural mechanisms of cognitive control within human prefrontal cortex. Proceedings of the National Academy of Sciences of the United States of America, 106(18), 7351-7356.

Chein, J. M., Moore, A. B., \& Conway, A. A. (2011). Domain-general mechanisms of complex working memory span. NeuroImage, 54(1), 550-559. doi:10.1016/j.neuroimage.2010.07.067

Cooper, R., \& Shallice, T. (2000). Contention Scheduling and the Control of Routine Activities. Cognitive Neuropsychology, 17(4), 297-338. doi:10.1080/026432900380427

Demarin, V., Kes, V., Morović, S., \& Zavoreo, I. (2009). Evaluation of aging vs dementia by means of neurosonology. Journal of the Neurological Sciences, 283(1-2), 9-12. doi:10.1016/j.jns.2009.02.006

Deckel, A., Cohen, D., \& Duckrow, R. (1998). Cerebral blood flow velocity decreases during cognitive stimulation in Huntington's disease. Neurology, 51(6), 1576-1583.

Dorst, J. J., Haag, A. A., Knake, S. S., Oertel, W. H., Hamer, H. M., \& Rosenow, F. F. (2008). Functional transcranial Doppler sonography and a spatial orientation paradigm identify the non-dominant hemisphere. Brain and Cognition, 68(1), 53-58. doi:10.1016/j.bandc.2008.02.123

Droste, D. W., Harders, A. G., and Rastogi, E. (1989). Two transcranial Doppler studies on blood flow velocity in both middle cerebral arteries during rest and the performance of cognitive tasks. Neuropsychologia 27: 1221-1230.

Duschek, S., Hadjamu, M., \& Schandry, R. (2007). Enhancement of cerebral blood flow and cognitive performance following pharmacological blood pressure elevation in chronic hypotension. Psychophysiology, 44(1), 145-153. doi:10.1111/j.1469-8986.2006.00472.x

Duschek, S., \& Schandry, R. (2004). Cognitive performance and cerebral blood flow in essential hypotension. Psychophysiology, 41(6), 905-913. doi:10.1111/j.1469-8986.2004.00249.x

Duschek, S., Werner, N., Kapan, N., \& Reyes de Paso, G. A. (2008). Patterns of cerebral blood flow and systemic hemodynamics during arithmetic processing. Journal of Psychophysiology, 22(2), 81-90. doi:10.1027/0269-8803.22.2.81

Fan, J., McCandliss, B. D., Fossella, J., Flombaum, J. I., \& Posner, M. I. (2005). The activation of attentional networks. NeuroImage, 26(2), 471-479. doi:10.1016/j.neuroimage.2005.02.004

Feldmann, D., Schuepbach, D., von Rickenbach, B., Theodoridou, A., \& Hell, D. (2006). Association between two distinct executive tasks in schizophrenia: A functional transcranial Doppler sonography study. BMC Psychiatry, 6doi:10.1186/1471-244X6-25

Haag, A., Moeller, N., Knake, S., Hermsen, A., Oertel, W. H., Rosenow, F., \& Hamer, H. M. (2010). Language lateralization in children using functional transcranial Doppler sonography. Developmental Medicine E Child Neurology, 52(4), 331-336. doi:10.1111/j.1469-8749.2009.03362.x 
Haupt, E. J. (2001). Laboratories for experimental psychology: Göttingen's ascendancy over Leipzig in the 1890s. In R. W. Rieber, D. K. Robinson, R. W. Rieber, D. K. Robinson (Eds.), Wilhelm Wundt in History: The Making of a Scientific Psychology (pp. 205-250). New York, NY US: Kluwer Academic/Plenum Publishers.

Helton, W. S. (2010). The relationship between lateral differences in tympanic membrane temperature and behavioral impulsivity. Brain and Cognition, 74(2), 75-78. doi:10.1016/j.bandc.2010.06.008

Helton, W. S., Hollander, T. D., Warm, J. S., Tripp, L. D., Parsons, K., Matthews, G., Dember, W. N., Parasuraman, R., \& Hancock, P. A. (2007). The abbreviated vigilance task and cerebral hemodynamics. Journal of Clinical \& Experimental Neuropsychology, 29(5), 545-552. doi:10.1080/13803390600814757

Hickey, C., van Zoest, W., \& Theeuwes, J. (2010). The time course of exogenous and endogenous control of covert attention. Experimental Brain Research, 201(4), 789-796. doi:10.1007/s00221-009-2094-9

Hitchcock, E. M., Warm, J. S., Matthews, G., Dember, W. N., Shear, P. K., Tripp, L. D., Mayleben, D. W., \& Parasuraman, R. (2003). Automation cueing modulates cerebral blood flow and vigilance in a simulated air traffic control task. Theoretical Issues in Ergonomics Science, 4(1-2), 89-112. doi:10.1080/14639220210159726

Hopkins, W. D., \& Fowler, L. A. (1998). Lateralized changes in tympanic membrane temperature in relation to different cognitive tasks in chimpanzees (Pan troglodytes). Behavioral Neuroscience, 112(1), 83-88. doi:10.1037/0735-7044.112.1.83

Horton-Lambirth, A., \& Roberts, A. E. (1998). Cerebral blood flow velocities modulate during cognitive tasks using vision and vision-like requirements: A TCD study. Psychobiology, 26(3), 183-189.

Just, M., \& Carpenter, P. A. (1995). The intensity dimension of thought: Pupillometric indices of sentence processing. In J. M. Henderson, M. Singer, F. Ferreira, J. M. Henderson, M. Singer, F. Ferreira (Eds.), Reading and language processing (pp. 182211). Hillsdale, NJ England: Lawrence Erlbaum Associates, Inc.

Kleider, H. M., Parrott, D. J., \& King, T. Z. (2010). Shooting behaviour: How working memory and negative emotionality influence police officer shoot decisions. Applied Cognitive Psychology, 24(5), 707-717. doi:10.1002/acp.1580

Knecht, S., Dräger, B. B., Flöel, A. A., Lohmann, H. H., Breitenstein, C. C., Henningsen, H. H., \& Ringelstein, E. B. (2001). Behavioural relevance of atypical language lateralization in healthy subjects. Brain: A Journal of Neurology, 124(8), 1657-1665. doi:10.1093/brain/124.8.1657

Kral, M. C., \& Brown, R. T. (2004). Transcranial Doppler ultrasonography and executive dysfunction in children with sickle cell disease. Journal of Pediatric Psychology, 29(3), 185-195. doi:10.1093/jpepsy/jsh020

Kral, M., Brown, R., Nietert, P., Abboud, M., Jackson, S., \& Hynd, G. (2003). Transcranial Doppler ultrasonography and neurocognitive functioning in children with sickle cell disease. Pediatrics, 112(2), 324-331. 
Latzman, R. D., \& Markon, K. E. (2010). The Factor Structure and Age-Related Factorial Invariance of the Delis-Kaplan Executive Function System (D-KEFS). Assessment, 17(2), 172-184. doi:10.1177/1073191109356254

Lust, J. M., Geuze, R. H., Groothuis, A. G., \& Bouma, A. A. (2010). Functional cerebral lateralization and dual-task efficiency-testing the function of human brain lateralization using ftcd. Behavioural Brain Research, doi:10.1016/j.bbr.2010.10.029

Lyon, G. R., \& Krasnegor, N. A. (Eds.) 2005. Attention, Memory, and Executive Function. Baltimore, MD: Paul H. Brookes Publishing Company.

Matthews, G., Warm, J., Reinerman-Jones, L., Langheim, L., Washburn, D., \& Tripp, L. (2010). Task engagement, cerebral blood flow velocity, and diagnostic monitoring for sustained attention. Journal of Experimental Psychology: Applied, 16, 187-203

McCartney, J. P., Thomas-Lukes, K. M., and Gomez, C. R. (1997). Handbook of Transcranial Doppler. New York, NY:Springer-Verlag.

Misteli, M., Duschek, S., Richter, A., Grimm, S., Rezk, M., Kraehenmann, R., \& ... Schuepbach, D. (2011). Gender characteristics of cerebral hemodynamics during complex cognitive functioning. Brain and Cognition, 76(1), 123-130. doi:10.1016/j.bandc.2011.02.009

Naqvi, N. H., \& Bechara, A. (2006). Skin Conductance: A Psychophysiological Approach to the Study of Decision Making. In C. Senior, T. Russell, M. S. Gazzaniga, C. Senior, T. Russell, M. S. Gazzaniga (Eds.) , Methods in mind (pp. 103-122). Cambridge, MA US: MIT Press.

Njemanze, P. C. (2006). Cerebral lateralisation for facial processing: Gender-related cognitive styles determined using Fourier analysis of mean cerebral blood flow velocity in the middle cerebral arteries. Laterality: Asymmetries of Body, Brain and Cognition, 12(1), 31-49. doi:10.1080/13576500600886796

Norman, D.A., \& Shallice, T. (1986). Attention to action: Willed and automatic control of behaviour. In R. Davidson, G. Schwartz, \& D. Shapiro, (Eds.), Consciousness and self regulation: Advances in research and theory, Vol. 4 (pp. 1-18). New York: Plenum.

Osaka, M., Osaka, N., Kondo, H., Morishita, M., Fukuyama, H., Aso, T., \& Shibasaki, H. (2003). The neural basis of individual differences in working memory capacity: an fMRI study. NeuroImage, 18(3), 789. doi:10.1016/S1053-8119(02)00032-0

Posner, M. I., \& Raichle, M. E. (1997). Images of Mind. New York, NY: W. H. Freeman

Posner, M. I., \& Rothbart, M. K. (2007). Research on Attention Networks as a Model for the Integration of Psychological Science. Annual Review of Psychology, 581-23. doi:10.1146/annurev.psych.58.110405.085516

Reinerman, L. E., Matthews, G.,Warm, J. S., Langheim, L. K., Parsons, K., Proctor, C. A., et al. (2006). Cerebral blood flow velocity and task engagement as predictors of vigilance performance. Proceedings of the Human Factors and Ergonomics Society, 50, 1254-1258.

Ringelstein, E. B., Kahlscheuer, B., Niggemeyer, E., and Otis, S. M. (1990). Transcranial Doppler sonography: Anatomical landmarks and normal velocity values. Ultrasound in Medicine and Biology 16, 745-761.

Risberg, J. (1986). Regional cerebral blood flow in neuropsychology. Neuropsychologia 24: 135-140. 
Sanchez, C. E., Schatz, J., \& Roberts, C. W. (2010). Cerebral blood flow velocity and language functioning in pediatric sickle cell disease. Journal of the International Neuropsychological Society, 16(2), 326-334. doi:10.1017/S1355617709991366

Saver, J. L., and Feldmann, E. (1993). Basic transcranial Doppler examination: Technique and anatomy. In V. L. Babikian and L. R. Wechsler (Eds.), Transcranial Doppler Ultrasonography (pp. 11-28). St. Louis, MO: Moseby.

Schneider, W., \& Chein, J. M. (2003). Controlled \& automatic processing: behavior, theory, and biological mechanisms. Cognitive Science, 27(3), 525. doi:10.1016/S03640213(03)00011-9

Schuepbach, D., Bader, J., Hell, D., \& Baumgartner, R. W. (2004). Cerebral hemodynamics and processing speed during category learning. NeuroReport: For Rapid Communication of Neuroscience Research, 15(7), 1195-1198. doi:10.1097/00001756200405190-00023

Schuepbach D, Boeker H, Duschek S, Hell D. (2007) Rapid cerebral hemodynamic modulation during mental planning and movement execution: evidence of time-locked relationship with complex behavior. Clinical Neurophysiology, 118, 2254-62.

Schuepbach, D., Huizinga, M., Duschek, S., Grimm, S., Boeker, H., \& Hell, D. (2009). Rapid cerebral hemodynamic modulation during set shifting: Evidence of time-locked associations with cognitive control in females. Brain and Cognition, 71(3), 313-319. doi:10.1016/j.bandc.2009.07.006

Schuepbach, D., Merlo, M. G., Goenner, F. F., Staikov, I. I., Mattle, H. P., Dierks, T. T., \& Brenner, H. D. (2002). Cerebral hemodynamic response induced by the Tower of Hanoi puzzle and the Wisconsin Card Sorting test. Neuropsychologia, 40(1), 39-53. doi:10.1016/S0028-3932(01)00074-4

Schuepbach, D., Weber, S., Kawohl, W., \& Hell, D. (2007). Impaired rapid modulation of cerebral hemodynamics during a planning task in schizophrenia. Clinical Neurophysiology, 118(7), 1449-1459. doi:10.1016/j.clinph.2007.03.001

Schultz, N. B., Phillips, H. A., \& Washburn, D. A. (2010). Lateral asymmetries in cerebral bloodflow velocity related to attention-task performance. Poster presented at the annual meeting of the Psychonomic Society (manuscript in preparation).

Schultz, N. B., Matthews, G., Warm, J. S., \& Washburn, D. A. (2009). A transcranial Doppler sonography study of shoot/don't-shoot responding. Behavior Research Methods, 41(3), 593-597. doi:10.3758/BRM.41.3.593

Sorond, F. A., Schnyer, D. M., Serrador, J. M., Milberg, W. P., \& Lipsitz, L. A. (2008). Cerebral blood flow regulation during cognitive tasks: Effects of healthy aging. Cortex: A Journal Devoted to the Study of the Nervous System and Behavior, 44(2), 179184. doi:10.1016/j.cortex.2006.01.003

Springer, S. P., \& Deutsch, G. (2001). Left Brain, Right Brain: Perspectives from Cognitive Neuroscience (5th edition). New York: W. H. Freeman and Company.

Stroobant, N., \& Vingerhoets, G. (2000). Transcranial doppler ultrasonography monitoring of cerebral hemodynamics during performance of cognitive tasks: A review. Neuropsychology Review, 10(4), 213-231. doi:10.1023/ A:1026412811036 
Szirmai I, Amrein I, Pálvőgyi L, Debreczeni R, Kamondi A. (2005). Correlation between blood flow velocity in the middle cerebral artery and EEG during cognitive effort. Cognitive Brain Research, 24, 33-40.

Tiemeier, H. H., Bakker, S. M., Hofman, A. A., Koudstaal, P. J., \& Breteler, M. B. (2002). Cerebral haemodynamics and depression in the elderly. Journal of Neurology, Neurosurgery \& Psychiatry, 73(1), 34-39. doi:10.1136/jnnp.73.1.34

Tripp, L. D., \& Warm, J. S. (2007). Transcranial doppler sonography. In R. Parasuraman, M. Rizzo, R. Parasuraman, M. Rizzo (Eds.), Neuroergonomics: The brain at work (pp. 8294). New York, NY US: Oxford University Press.

Turtle, A. M. (1997). Tachistoscope. In R. Bund \& D. Warner (Eds). Instruments of Science: A Historical Encyclopedia (pp. 595-596). New York: NY US: Garland Publishing Inc.

Unsworth, N., \& Engle, R. W. (2008). Speed and Accuracy of Accessing Information in Working Memory: An Individual Differences Investigation of Focus Switching. Journal of Experimental Psychology. Learning, Memory \& Cognition, 34(3), 616-630. doi:10.1037/028-7393.34.3.616

Vanman, E. J., Saltz, J. L., Nathan, L. R., \& Warren, J. A. (2004). Racial discrimination by low-prejudiced Whites facial movements as implicit measures of attitudes related to behavior. Psychological Science, 15(11), 711-714.

doi:10.1111/j.0956-7976.2004.00746.x

Vingerhoets, G., \& Luppens, E. (2001). Cerebral blood flow velocity changes during dichotic listening with directed or divided attention: A transcranial Doppler ultrasonography study. Neuropsychologia, 39(10), 1105-1111. doi:10.1016/S00283932(01)00030-6

Vul, E., Harris, C., Winkielman, P., \& Pashler, H. (2009). Puzzlingly high correlations in fMRI studies of emotion, personality, and social cognition. Perspectives on Psychological Science, 4(3), 274-290.

Walsh, V., \& Pascual-Leone, A. (2006). Transcranial Magnetic Stimulation: A Neurochronometrics of Mind. Cambridge, MA: MIT Press.

Walter, K. D., Roberts, A. E., \& Brownlow, S. S. (2000). Spatial perception and mental rotation produce gender differences in cerebral hemovelocity: A TCD study. Journal of Psychophysiology, 14(1), 37-45. doi:10.1027//0269-8803.14.1.37

Warm, J. S., Matthews, G., \& Parasuraman, R. (2009). Cerebral hemodynamics and vigilance performance. Military Psychology, 21(Suppl 1), S75-S100. doi:10.1080/08995600802554706

Warm, J. S., \& Parasuraman, R. (2007). Cerebral hemodynamics and vigilance. In R. Parasuraman \& M. Rizzo (Eds.), Neuroergonomics: The brain at work (pp. 146-158). New York: Oxford University Press.

Warm, J. S., Parasuraman, R., \& Matthews, G. (2008). Vigilance Requires Hard Mental Work and Is Stressful. (Cover story). Human Factors, 50(3), 433-441. doi:10.1518/001872008X312152

Washburn, D. A., \& Schultz, N. B. (2008, November). Inattention vs. task-irrelevant attention in the vigilance decrement. Paper presented at the annual meeting of the Psychonomic Society, Chicago, IL. Manuscript in preparation. 
Washburn, D. A., Smith, J., \& Taglialatela, L. A. (2005). Individual Differences in Metacognitive Responsiveness: Cognitive and Personality Correlates. Journal of General Psychology, 132(4), 446-461

Washburn, D. A., \& Taglialatela, L. A. (2006). Attention as it is manifest across species. In T. R. Zentall \& E. Wasserman (Eds.), Comparative Cognition: Experimental Explorations of Animal Intelligence (pp. 127-142), New York: Oxford University Press.

Wiebe, S. A., Sheffield, T., Nelson, J., Clark, C. C., Chevalier, N., \& Espy, K. (2011). The structure of executive function in 3-year-olds. Journal of Experimental Child Psychology, 108(3), 436-452. doi:10.1016/j.jecp.2010.08.008 


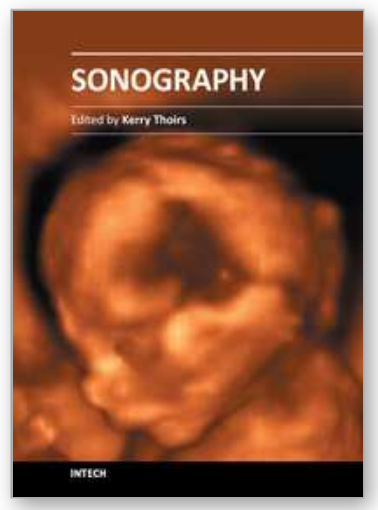

\author{
Sonography \\ Edited by Dr. Kerry Thoirs
}

ISBN 978-953-307-947-9

Hard cover, 346 pages

Publisher InTech

Published online 03, February, 2012

Published in print edition February, 2012

Medical sonography is a medical imaging modality used across many medical disciplines. Its use is growing, probably due to its relative low cost and easy accessibility. There are now many high quality ultrasound imaging systems available that are easily transportable, making it a diagnostic tool amenable for bedside and office scanning. This book includes applications of sonography that can be used across a number of medical disciplines including radiology, thoracic medicine, urology, rheumatology, obstetrics and fetal medicine and neurology. The book revisits established applications in medical sonography such as biliary, testicular and breast sonography and sonography in early pregnancy, and also outlines some interesting new and advanced applications of sonography.

\title{
How to reference
}

In order to correctly reference this scholarly work, feel free to copy and paste the following:

David A. Washburn, Natasha B. Schultz and Holly A. Phillips (2012). Transcranial Doppler Sonography in Studies of Mental Effort, Sonography, Dr. Kerry Thoirs (Ed.), ISBN: 978-953-307-947-9, InTech, Available from: http://www.intechopen.com/books/sonography/transcranial-doppler-sonography-in-studies-of-mentaleffort

\section{INTECH}

open science | open minds

\section{InTech Europe}

University Campus STeP Ri

Slavka Krautzeka 83/A

51000 Rijeka, Croatia

Phone: +385 (51) 770447

Fax: +385 (51) 686166

www.intechopen.com

\section{InTech China}

Unit 405, Office Block, Hotel Equatorial Shanghai

No.65, Yan An Road (West), Shanghai, 200040, China

中国上海市延安西路65号上海国际贵都大饭店办公楼405单元

Phone: +86-21-62489820

Fax: +86-21-62489821 
(C) 2012 The Author(s). Licensee IntechOpen. This is an open access article distributed under the terms of the Creative Commons Attribution 3.0 License, which permits unrestricted use, distribution, and reproduction in any medium, provided the original work is properly cited. 